\title{
Surfing and dining on the "plastisphere": Microbial life on plastic marine debris
}

\author{
Grazia Marina Quero, ${ }^{1}$ Gian Marco Luna² \\ ${ }^{1}$ Stazione Zoologica Anton Dohrn, 80121 Villa Comunale, Naples; ${ }^{2}$ Institute of Marine Sciences (CNR-ISMAR), National Research \\ Council, Largo Fiera della Pesca 2, 60125 Ancona, Italy \\ *Corresponding author: gianmarco.luna@an.ismar.cnr.it
}

\begin{abstract}
Plastic marine debris represents a global threat for the marine environment, having serious consequences for the ocean, the wildlife and the human health. While the plastics distribution, fate, persistence and toxicity mechanisms for the marine fauna have been more studied in the last decade, small efforts have been devoted to identify and characterize marine microbes that colonize plastic and microplastic debris in the ocean, and their potential to degrade plastics. Here we review the knowledge on the microbial biodiversity and degradation mechanisms of marine plastic debris, and present data, based on metagenomic analyses, on the distribution patterns of genes potentially involved in microbially-mediated plastic degradation in coastal locations across the global ocean. Most studies on plastic-colonizing microbes have focused on seawater rather than sediment, with most studies underlining striking differences in composition between assemblages attached to plastic particles and those in the surrounding environment. The diversity of microbes attached to plastic is high, and the core epiplastic microbial assemblages include often hydrocarbon-degrading bacteria, as well as prokaryotic and eukaryotic phototrophs. Several marine microbes have shown to be able to degrade or deteriorate plastic in the laboratory, or to grow on plastic as the only source of carbon, while indirect evidences suggest that microbially-mediated degradation of recalcitrant plastics also occur in the ocean, though at very low rates. Metagenomic analyses show that plastic degradation-related genes are present in microbial assemblages in several coastal ocean sites, with relative abundance related to the magnitude of plastic pollution at each site. Further research is required to study microbial plastic-degraders in the marine ecosystem, to decipher and exploit the potential of microbial consortia to degrade or mineralize plastic compounds, and to better understand the fate and residence times of plastic waste in the ocean.
\end{abstract}

Key words: Plastics; microbes; metagenomics; biodegradation.

Received: December 2017. Accepted: December 2017.

\section{PLASTICS IN THE OCEAN}

Plastic is today recognized as the most abundant form of man-made debris in the sea (Barnes et al., 2009), with the mass of land-based plastic waste entering the ocean recently estimated to be in the range 4.8 to 12.7 million metric tons per year (Jambeck et al., 2015). Early reports on the occurrence of plastics in the marine environment can be traced back to the 70s: Carpenter and Smith (1972) reported on the presence of an average 3500 plastic particles per square kilometer in the Sargasso Sea surface, collected through a neuston net in an area located far from obvious pollution sources from land. The authors speculated that the source of the particles could have been the dumping of waste from cities or by the cargo and passenger ships, given that some of the sampled areas were within major shipping lanes from Europe to America. Later on, Gregory and Ryan (1997) reported that plastics accounted for a significant proportion (from 60 to $80 \%$ ) of the total debris encountered in the seas of the Southern Hemisphere. Since then, a number of papers have increasingly documented the presence and spread of plastic debris across the marine environment (Galgani et al., 2000;
Moore et al., 2001; Moore et al., 2002; Willis et al., 2017; Worm et al., 2017). However, the threat of plastics to the marine environment has been ignored for a long time, and it is only in more recent years that its serious consequences for the ocean, the wildlife and the human health have started to being recognized (Derraik, 2002).

Plastic debris occurs along the coastlines (Browne et al., 2010), at the sea surface (Law et al., 2014) and on the sea floor (Stefatos et al., 1999; Galgani et al., 1996; Claessens et al., 2011; Cau et al., 2017), and even in remote areas such as the open ocean surface far from land (Cozar et al., 2014). Plastic reaches the ocean both in the form of large visible debris ("macro") that is larger than 1-5 mm, or in the form of small particles or fragments called "micro-plastics" (having dimensions typically $<1$ $5 \mathrm{~mm}$ ) (Browne et al., 2010), despite globally accepted definitions for these categories are yet to be established. In a recent review that compared the methodologies used in 68 studies for the quantification of microplastics in the marine environment, Hidalgo-Ruz et al. (2012) highlighted that most of them reported two main size ranges of microplastics, $500 \mu \mathrm{m}-5 \mathrm{~mm}$ and 1-500 $\mu \mathrm{m}$, or fractions thereof that are retained on filters, confirming that there is still not a universally adopted size range to define 
microplastics. Thus, the term "microplastics" is used in the literature to include a surprisingly broad range of particles sizes from $\sim 5 \mathrm{~mm}$ to few microns in diameter (Andrady 2017). A more practical scheme to classify plastics debris in the aquatic environment has been proposed by the European MSFD Technical Subgroup on Marine Litter (reported in Van Cauwenberghe et al., 2015), a scheme which also includes the category "mesoplastics" in the size range $5 \mathrm{~mm}-2.5 \mathrm{~cm}$. Plastic debris enters the marine environment in a wide range of sizes, in the micrometer to meter range (Hidalgo-Ruz et al., 2012), as well in a broad range of color, shape, chemical composition and specific gravity. As far as the small size plastic debris is concerned, microplastics are typically categorized into primary and secondary (Andrady, 2017). The primary ones are purposefully created, and are directly released into the environment as small plastic particles. They are typically industrially manufactured, such as microbeads used in cosmetics, personal care, abrasive media and other industries, or as virgin plastics pellets for fabrication of products, and enter the environment via leakage during manufacture, transportation or use. A recent study estimated that between 15 and $31 \%$ of all of the microplastics in the oceans could originate from primary sources, and estimated the global release of primary microplastics into the ocean at 1.5 million tons per year (Boucher and Friot, 2017). The secondary microplastics, that are believed to be far more abundant in the ocean, originate from fragmentation of larger plastic debris items either during their use of products, or due to weathering degradation of their litter in the environment. Examples of secondary microplastics include the textile fiber fragments released from synthetic fabrics during washing, degrading of agricultural mulch films, and the weathering breakdown of plastic litter in the marine environment (Andrady, 2017). However, still different definitions for primary and secondary microplastics exist in the literature (Boucher and Friot, 2017). This holds especially true for those microplastics that originate from the abrasion of larger plastic objects during manufacturing, use or maintenance (such as the erosion of tyres when driving, that account for a significant source of plastics in the ocean) that are classified as primary by some authors (Sundt et al., 2014; Boucher and Friot, 2017) or secondary by others (GESAMP, 2015). Sources of plastics and microplastics in the ocean are multiple, and the estimates of pollution sources and sinks are still uncertain.

Once plastic items reach the marine environment (Fig. 1), positively buoyant ones will tend to accumulate at the sea surface, where they are transported by winds and surface water currents over long distances, whereas negatively buoyant items sink out of the water column to the sediments below (Clark et al., 2016). It has to be noted that, among the classes of plastic that are commonly encoun- tered in the marine environment, only a few have specific gravity lower than that of seawater (such as polyethylene, $\mathrm{PE}$ and polypropylene, $\mathrm{PP}$ ) and are thus positively buoyant, while many of them (such as Polyvinyl Chloride, PVC) are denser and tend to submerge in the water column (Andrady, 2011). Because of fouling by micro- (Lobelle and Cunliffe, 2011) and macro-organisms and the adherence of particles, positively buoyant plastics can, over a timescale of weeks to months, become negatively buoyant and sink to the seafloor down to the deep sea (Woodall et al., 2014). Plastic fragments are considered to be quite stable and highly durable (Sivan 2011), potentially lasting hundreds to thousands of years in the aquatic environment (Barnes et al., 2009). However, the exposure of plastic objects on the surface waters to UV radiation from sunlight results typically in their photodegradation by oxidation (Gewert et al., 2015) (Fig. 1). Further degradation, fragmentation and erosion of the plastic debris are caused by physical forces (such as wave action, wind and abrasion with sand), biological breakdown and chemical weathering. During fragmentation and weathering of plastic debris in seawater, nano-scale particles are also generated (Gigault et al., 2016), although their abundance has not been quantified yet in the global ocean (Ter Halle et al., 2017). This finding calls for further investigations on the fate, behavior and hazard posed by nano-plastics in the marine environment.

In addition to the concerns raised by toxicity of the plastic polymers and their additives (often intentionally added during manufacturing or processing to improve performance; Gewert et al., 2015) for marine life (through ingestion and other mechanisms), plastics and microplastics also adsorb and accumulate toxic chemicals, such as persistent organic pollutants (Bakir et al., 2012), transporting them across the ocean and vehiculating to the marine organisms that ingest them (Mato et al., 2001). Recent findings showed that organisms belonging to three different phyla that live on the deep-sea floor do ingest and internalize plastic microfibers, demonstrating the even the deep sea and its inhabitants are being exposed to this type of anthropogenic waste (Taylor et al., 2016). Compared to meso- and macroplastic debris, microplastic is more prone to adsorb waterborne contaminants due to its higher surface area to volume ratio (Gewert et al., 2015). Recent studies have also paid attention to the concept of plastic providing a novel means of transport for microorganisms, including pathogenic ones, across the marine environment, consequently acting as a possible vector for the spread of these microbes that can facilitate the diffusion of infectious diseases (Keswani et al., 2016).

Here, we review the current knowledge on microbes that are associated with plastic debris in the ocean. While plastic debris can be colonized by a wide variety of microbes, belonging to the three domains of life, including microbial eukaryotes (such as diatoms; Ober- 
beckmann et al., 2016), we focus our review on the prokaryotic (Bacteria and Archaea) plastic colonizers. Also, given that excellent reviews have already covered the type and biodiversity of microbes that colonize plastic and microplastic fragments in aquatic ecosystems (Oberbeckmann et al., 2015; Harrison et al., 2018), we focus here on summarizing the knowledge on the identity of those marine bacteria, and their genetic path- ways, that colonize and potentially degrade (i.e., cause the plastic chemical breakdown) or deteriorate (i.e., cause loss of physical integrity; Rummel et al., 2017) plastic debris. Lastly, based on metagenomic analyses, we present data about the distribution patterns of some genes that are potentially involved in microbially-mediated plastic degradation in several coastal locations across the global ocean.

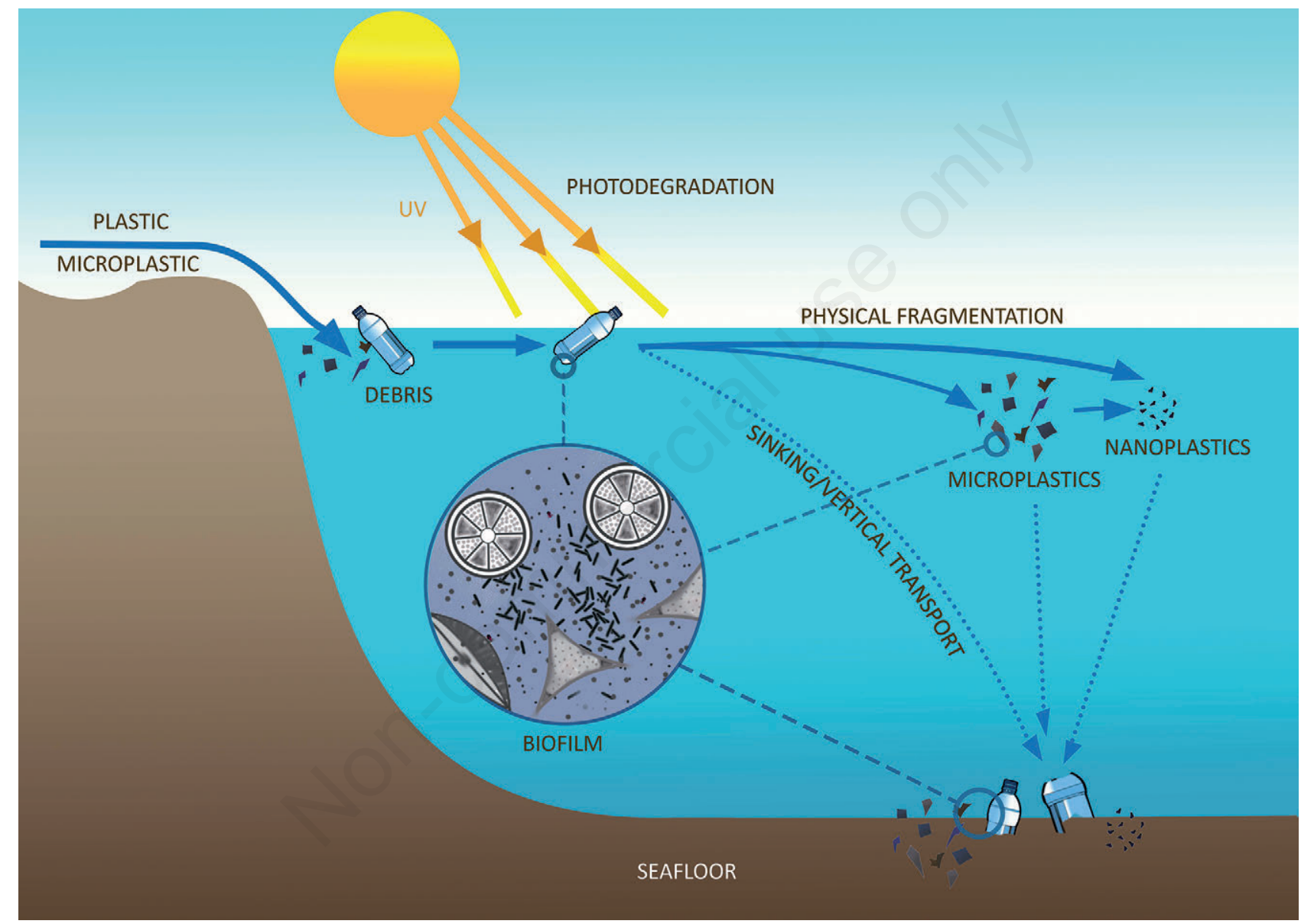

Fig. 1. Schematic drawing that summarizes the fate of plastic debris in the marine environment, with a focus on the interactions between plastics and microbes. Plastic debris reaches, mostly from land-based sources, the marine environment in the form of visible debris and of smaller pieces that are not visible to the naked eye (microplastics). Once reached the ocean, floating plastic is readily colonized by a wide variety of microbes, including members from the three domains of life (archaea, bacteria and eukarya). Marine viruses can likely be members of the epiplastic assemblages, but reports on this biotic component on plastic are still not available in the literature. The hydrophobic nature of plastic surfaces stimulates rapid formation of the microbial biofilm, which then drives succession of other microand macro-organisms (among which diatoms and invertebrates; Reisser et al., 2014). This biofilm contributes significantly to determine the subsequent fate of the plastic items (down to the millimeter-size), by influencing their ballasting ability, by likely mediating their degradation and fragmentation to smaller particles (that is believed to occur through a combination of physical, chemical and biological processes) and by affecting the toxicity level. Fragmentation produces smaller and smaller plastic fragments, down to the nanometers size. Transport of plastic items to the seafloor occur through several ways, although the transport mechanisms of biofouled microplastics to the ocean interior still remain unclear. A recent model that explains the sinking vertical mechanisms of microplastic has been published by Kooi et al. (2017). Once reached the seafloor, the plastic debris will undergo colonization by the sediment microbes (Harrison et al., 2014), degradation and/or permanent sequestration. However, sediments will not necessarily represent the ultimate sink for plastic debris, because of the removal and/or digestion by benthic animals living in the sediments (Rummel et al., 2017). 


\section{MICROBIAL LIFE ON PLASTIC DEBRIS}

Once in the marine environment, microbes readily (i.e., within minutes to hours) colonize the aquatic plastic debris, and the members of these biofilm communities can include pathogenic, toxic, invasive or plastic degrading-species (Oberbeckmann et al., 2016). To date, the largest fraction of studies on plastic-colonizing microbes have focused on seawater samples (Dang and Lovell, 2000; Lee et al., 2008; Carson et al., 2013; Zettler et al., 2013; Amaral-Zettler et al., 2015; Bryant et al., 2016), with most of them underlining the striking differences in the community composition of bacterial taxa on plastic particles with respect to the surrounding water column (Zettler et al., 2013; Bryant et al., 2016; Oberbeckmann et al., 2016). Moreover, some of those studies have also used shotgun metagenomic to perform microbial functional gene comparisons, and have showed that plastic-inhabiting microbes have a gene repertoire that is enriched for traits necessary for a surface-attached lifestyle (Bryant et al., 2016). Conversely to seawater, only little information is available for plastic-associated communities in sediments (Harrison et al., 2014; De Tender et al., 2015; De Tender et al., 2017).

In seawater, early studies on microbial life attached to plastic surfaces in the ocean reported that typical early colonizers are members of the Gammaproteobacteria and Alphaproteobacteria, with an increasing trend in Bacteroidetes during time (Dang and Lovell, 2000; Lee et al., 2008), the so-called "primary" and "secondary colonizers", respectively (Lobelle and Cunliffe, 2011; Oberbeckmann et al., 2015). These findings were confirmed by Dang et al. (2008) who identified early biofilm communities on PVC samples as belonging to the order of Rhodobacterales (Alphaproteobacteria), in particular to the clade Roseobacter. The first study that investigated microbial biofilms on plastic marine debris using modern techniques of massive DNA sequencing was carried out by Zettler and colleagues (2013). This study showed a huge diversity within plastic-associated microbial communities in the North Atlantic Subtropical Gyre, and provided the first detailed picture of the microbial epiplastic assemblages (that the authors termed "plastisphere") attached to fragments of PP and PE, which appeared to be highly represented by prokaryotic and eukaryotic phototrophs (the cyanobacteria Phormidium and Rivularia, as well as numerous diatoms such as Navicula, Nitzschia, Sellaphora, Stauroneis and Chaetoceros) and typical free-living bacterial taxa (e.g., Pelagibacter). They also highlighted a remarkable presence of other protists and showed, by combining SEM and NGS, a colonization by stalked suctorian ciliates covered with bacteria. Moreover, they also identified a "core" plastisphere community that included hydrocarbon-degrading bacteria (Phormidium sp., Pseudoalteromonas sp. on PP and PE fragments, and $H y$ phomonadaceae on PMD and PP), pointing out a possible role of plastic-inhabiting microbes in the degradation of those polymers. Oberbeckmann et al. (2016) observed the changes in plastic-associated microbial communities after deploying PET drinking bottles in different stations and seasons in the North Sea. Although abundant PET-colonizing taxa belonged to the bacterial phylum Bacteroidetes (e.g., Flavobacteriaceae, Cryomorphaceae, Saprospiraceae) and to the diatoms Coscinodiscophytina and Bacillariophytina, PET-colonizing prokaryotic and eukaryotic communities varied greatly with space and time. These results, and the comparison of PET communities with glass-colonizing communities in the same experiment, suggested that microbial assembly on plastics is both driven by conventional marine biofilm processes (thus, not necessarily by a selection of plastic-specific colonizers), although a small proportion of taxa (members of the Cryomorphaceae and Alcanivoraceae) were significantly discriminant of PET, leading to speculate that these groups may directly interact with the PET substrate. In the recent study by Bryant et al. (2016) in the North Pacific Subtropical Gyre, plastic-attached communities were shown to be dominated by few metazoan taxa and by several photoautotrophic and heterotrophic protists and bacteria. Bryozoa, Cyanobacteria, Alphaproteobacteria and Bacteroidetes dominated on all the plastic items. As similarly observed for bacterial taxa by Zettler et al. (2013), with the only major exception of Vibrionaceae, and confirmed by Bryant et al. (2016) after reannotation of their amplicon data, the authors identified the most abundant prokaryotic groups as Cyanobacteria (belonging to genera Phormidium, Rivularia and Leptolyngbya) and Alphaproteobacteria (with Rhodobacteraceae and Hyphomonadaceae as the most represented families), followed by Flavobacteriia, Cytophagia, Sphingobacteriia, Gammaand Deltaproteobacteria. In only one sample, the Bacteroidetes genera Tunicatimonas and Tenacibaculum made up approximately $10 \%$ of one sample.

Only few, recent studies described the composition of microbial assemblages on plastic items retrieved from sediments. In a two-weeks experiment of exposure of microplastics in sediments of the North Sea, Harrison et al. (2014) found that the dominant colonisers on LDPE (Low Density PolyEthylene) microplastic belonged to the genera Arcobacter and Colwellia. Seafloor plastic samples collected in the North Sea by De Tender et al. (2015) showed a wide variation in bacterial community composition, with a dominance of Alpha- and Gammaproteobacteria and Bacteroidetes. De Tender et al. (2017) explored the taxonomic composition of bacterial (and fungal) communities on PE plastic sheets and dolly ropes during long-term exposure on the seafloor, at a harbor and at an offshore location in the North Sea. Bacterial communities on PE sheets in the harbor changed over time, with a gradual decrease in the relative abundance of primary colonizers (Alphaand Beta-proteobacteria) and an increase in secondary col- 
onizers (Bacteroidetes), according to previous studies (Dang and Lovell, 2000; Lee et al., 2008; Lobelle and Cunliffe, 2011; Oberbeckmann et al., 2015). The core bacteriome included the genera Arenicella and Methylotenera, in addition to Sulfurovum and Maritimimonas in the early stage, Robiginitomaculum in the middle stage, and Sulfitobacter and Psychroserpens in the late stage of exposure. A different picture was observed in the offshore waters, where the bacterial community was dominated by Flavobacteria and Gammaproteobacteria, and no temporal changes could be observed. In the offshore, the core microbiome included Bacteroidetes (Flavobacteriaceae) and Proteobacteria (Caulobacterales, Hyphomonadaceae Rhodobacteraceae and Alcanivoracaceae).

\section{PLASTICS DEGRADATION BY MARINE MICROBES}

Owing to the slow rates of degradation and breakdown, marine plastics can persist long in the environment; however, real data on the kinetics of mineralization of plastics in the marine environment are still virtually not existent (Andrady, 2011). Rates of conventional plastics (i.e., those plastics derived from petrochemicals) degradation by bacteria performed even in optimized laboratory conditions are extremely slow (reviewed in Krueger et al., 2015), indicating that plastics is highly recalcitrant to biodegradation. Recent studies, based on scanning electron observations of the surface of plastic particles, have pointed out the potential role of marine bacterial populations in contributing to plastic degradation, thus potentially intervening in the fragmentation dynamics (Zettler et al., 2013). This hypothesis is based on the evidence that pits visualized in the plastic debris conformed to bacterial shapes, thus suggesting an active hydrolysis of the hydrocarbon polymer. This finding was later confirmed by Reisser et al. (2014) in another study carried out in Australia in a wide number of coastal and oceanic plastic samples. The more recent evidences for plastic degradation and assimilation by the bacterium Ideonella sakaiensis, that is able to efficiently convert PET into its two environmentally benign monomers (terephthalic acid and ethylene glycol) (Yoshida et al., 2016), are providing further impetus to perform research in this area, and are suggesting the ecological and biotechnological importance of exploiting novel polymer-degrading taxa that are likely to populate the terrestrial and aquatic ecosystems.

The ability of microbes to degrade plastic is known since several decades, with the first studies reporting the ability of certain bacteria and fungi to degrade plastic polymers (Harvey et al., 1949; Booth et al., 1968). Insights into the distribution, identity and potential of plastic-degrading microbes in the marine environment have been later reported over the following decades. Most of those studies have been based on the isolation and in vitro testing of sin- gle strains isolated from the marine environment and the nearby areas. Balasubramanian et al. (2010) recently isolated, by enrichment techniques from samples consisting of degraded polyethylene and soil in plastic waste dumped sites in the Gulf of Mannar (India), bacteria (identified as Arthrobacter sp. and Pseudomonas sp.) that efficiently degrade high-density polyethylene (HDPE). Several comprehensive reviews have been focused on the microorganisms and their enzymes that are able to degrade petroleum-based plastic polymers (Shah et al., 2008; Sivan, 2011), or on the types and mechanisms of degradation, including biodegradation, and the factors that influence these processes (Singh and Sharma, 2008). Krueger et al. (2015) have provided a comprehensive overview of the current knowledge on the enzymes implicated in the biodegradation of conventional plastics, as well as on the mechanisms of biodegradation of several of the most common plastic types, both hydrolysable and non-hydrolysable. They also state that, despite the increasing amount of studies performed in the last decades, information about biodegradation and the biochemical breakdown of synthetic, persistent conventional plastics is still scarce. Plastic degradation by microbes is believed to occur through different pathways, depending also on the type of polymer. Restrepò-Flòrez et al. (2014) recently provided a review on the microbial degradation of $\mathrm{PE}$, highlighting that biodegradation of this type of plastic is complex and not fully understood, and that its biodegradation in the environment maybe a cooperative process, mediated by different interacting types of microorganisms.

While several studies have been performed in vitro following isolation of plastic degraders, studies of microbial degraders of plastic items performed directly in the marine environment are rarer. In a recent study, Bryant et al. (2016) identified, in the North Pacific Gyre, a number of putative xenobiotic biodegradation genes that were significantly more abundant on the plastic-attached microbes rather than on the non-attached microbes that lived in the surrounding seawater. These genes included including homogentisate 1,2-dioxygenase, N-ethylmaleimide reductase, a cytochrome P450 and 2,4-dichlorophenol 6-monooxygenase. In particular, homogentisate 1,2-dioxygenase is an enzyme that has been implicated in the degradation of polycyclic aromatic hydrocarbons, as well as styrene, while 2,4Dichlorophenol 6-monooxygenase is a hydroxylase involved in the degradation of chlorinated aromatic pollutants. The genes encoding the two subunits of protocatechuate 3,4-dioxygenase, an aromatic-ring-cleaving enzyme implicated in lignin degradation, were also observed in plastic metagenome samples. While the authors could not discern whether these genes serve for microorganisms residing on plastic debris to degrade plastics, or to co-metabolize the adsorbed pollutants, this study is the first that reported candidate genes that are likely involved in plastic degradation in the oceanic environment. 
To verify the presence and prevalence of plastic degradation-related genes in marine microbial assemblages, we looked for the presence and prevalence of GO (Gene Ontology) terms and KEGG enzymes corresponding to these genes (more details in Supplementary Tab. 2) within a set composed by 13 selected metagenomes that are made available by the Ocean Sampling Day initiative (Kopf et al., 2015), a project that simultaneously analyzed microbial community composition and functional traits in more than one hundred sites around the global coastal ocean (Fig. 2A).

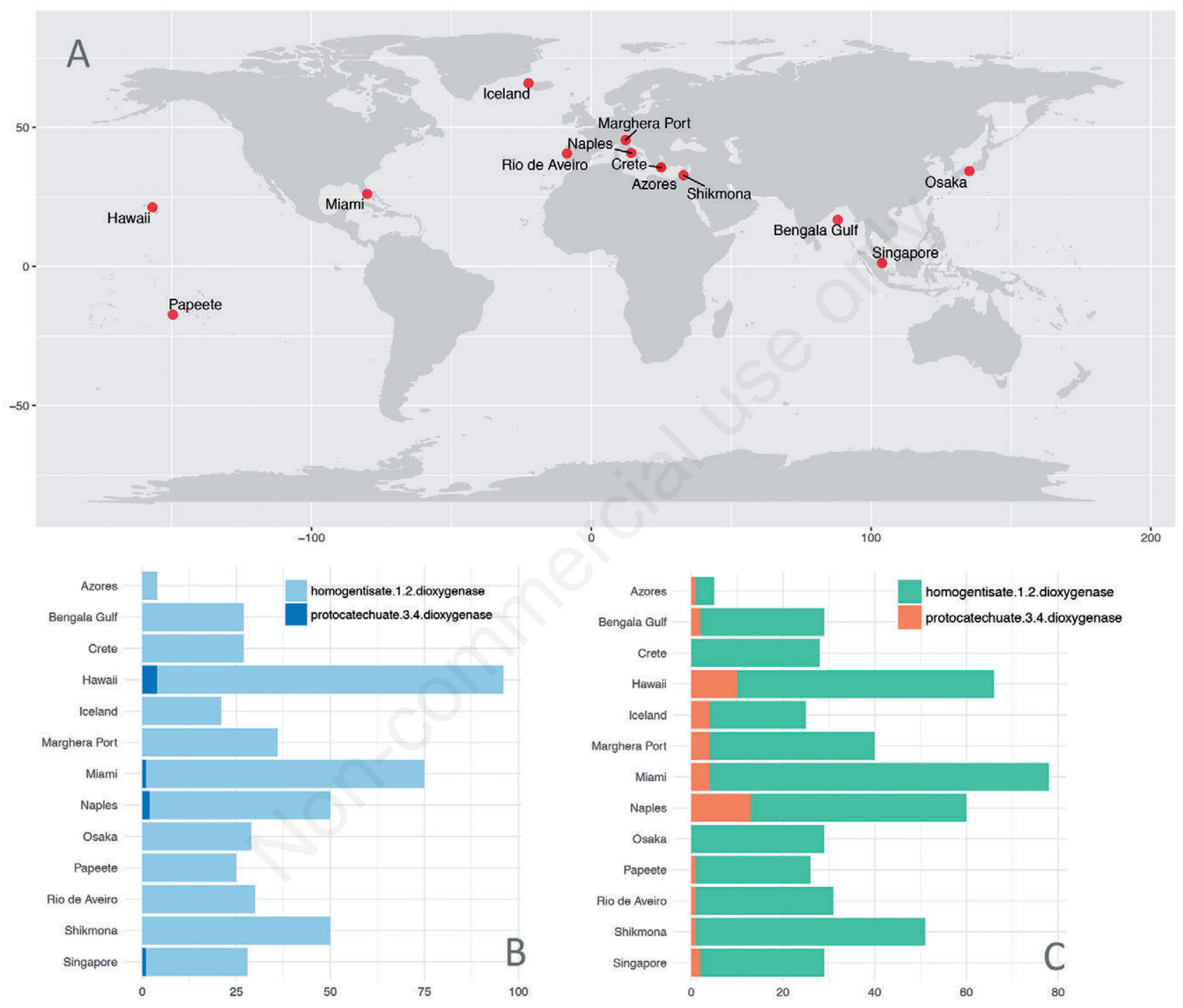

Fig. 2. A survey of the presence and the prevalence, within marine metagenomes from coastal sites, of microbial genes that are potentially associated with plastic degradation. A) Location of the 13 sampling sites in the coastal ocean considered in our study. B) and C) Presence and distribution of the gene "homogentisate 1,2-dioxygenase" and "protocatechuate 3,4-dioxygenase" in the different sites, reported as number of observations of the corresponding GO terms (B) and KEGG Enzyme (C). The metagenomes here analyzed are taken from the Ocean Sampling Day (OSD) database available here: https:/www.ebi.ac.uk/metagenomics/projects/ERP009703. "InterPro matches" and "Complete GO annotation" files were downloaded from the following link: https://www.ebi.ac.uk/metagenomics/projects/ERP009703. The OSD site original name were here changed for facility of reading as follows: OSD4, Naples; OSD5, Crete; OSD7, Papeete; OSD28, Bengala Gulf; OSD37, Miami; OSD56, Hawaii; OSD69, Marghera Port; OSD95, Singapore; OSD96, Azores; OSD106, Iceland; OSD111, Rio de Aveiro; OSD123, Shikmona; OSD124, Osaka. More details about the samples, including information about the total MG reads number and the total GO annotated terms per each of the samples, are provided in Supplementary Tab. 1. The map and barplots were obtained with the 'maps' (https:/CRAN.R-project.org/package=maps), 'ggplot2' (http://ggplot2.org), 'ggrepel' (http://github.com/slowkow/ ggrepel) and 'ggplot2', 'reshape2' (http://www.jstatsoft.org/v21/i12/paper) and 'RColorBrewer' (https://CRAN.R-project.org/package= RColorBrewer) packages, respectively, using the R programming language and environment (R Core Team, 2017). 
The results are shown in Fig. 2B (for GOs) and 2C (for KEGG). The results showed that neither KEGG enzymes nor GO terms related to 2,4-dichlorophenol 6-monooxygenase, N-ethylmaleimide reductase and cytochrome $\mathrm{p} 450 / \mathrm{NADPH}$-cytochrome $\mathrm{p} 450$ reductase were observed throughout the dataset. On the other hand, KEGG enzymes and GO terms observations for homogentisate 1,2-dioxygenase-related counts ranged from 4 (Azores) to 92 (Hawaii) while, for the protocatechuate 3,4-dioxygenase, these were only observed as GOs in the samples from Naples $(\mathrm{n}=2)$, Miami $(\mathrm{n}=4)$, Hawaii $(\mathrm{n}=1)$ and Singapore $(\mathrm{n}=1)$ and, as KEGG enzymes, ranged from 0 (Crete and Osaka) to 13 (Naples). Homogentisate 1,2-dioxygenase-related GO terms and enzymes were found in all the considered samples, with the highest number observed in sites such as Hawaii, Miami, Naples and Shikmona (Fig. 2B and C). These sites are known in the literature to be particularly polluted by plastics (Eriksen et al., 2014; van der Hal et al., 2017). Protocatechuate 3,4-dioxygenase - related GO terms were found in Hawaii, Miami, Naples and Singapore (Fig. 2B). KEGG enzymes codes for the same function were retrieved in all the samples except for Crete and Osaka, with the highest number of observations observed in Hawaii, Naples, Miami, Marghera and Iceland (Fig. 2C). Although it is not possible to link directly these metagenomic data with plastic degradation processes occurring in the studied sites, these results suggest that degradation potential for plastic debris is ubiquitously present in marine microbial assemblages from almost all the coastal ocean, and that the relative abundance of microbial degrading genes could be related to the magnitude of plastic pollution within each site. Further studies are required, combining omics techniques with in situ degradation rate measurements, to fully elucidate the potential of plastic breakdown of marine microbial assemblages.

\section{CONCLUSIONS AND FUTURE PERSPECTIVES OF RESEARCH}

Whether microbial plastic degradation or the use of plastic-associated chemicals are relevant processes in the oceans, and which environmental factors are able to influence these activities, are fundamental, yet still unanswered questions. Little is known about the identity of microbes that colonize macro- and microplastic debris in the ocean, and on their ability to degrade, transform or eventually assimilate plastics in the marine environment, including the time scales of degradation and the type and fate of the degradation products. A recent study has shown that tailored indigenous marine communities comprising polymer and hydrocarbon degrader species had the potential to degrade naturally weathered PE films, suggesting a more relevant role for microbial consortia, rather than single bacterial species, to degrade recalcitrant plastic
(Syranidou et al., 2017). The potential applications of the results gathered from researches on plastic-degrading microbially-mediated processes are not straightforward. In fact, the use of plastic-degrading microbes in the frame of large-scale applications to clean the ocean is obviously not a feasible strategy and, analogously, the use of plastic-degrading microbes is today not a reliable and effective alternative to conventional plastic recycling, that is based on plastic melting and regeneration. However, as the system of plastic recycling is still not fully exploited and optimized, the potential of microorganisms to degrade plastic has to be explored to learn more about degradation pathways, to ensure the safer disposal of plastic waste (via biodegradation), and to develop materials that decompose more readily than conventional plastic polymers. In addition, ecological research in this area is necessary to better understand the fate and the residence times of plastic waste in the ocean, and to predict the ecological consequences of plastic and microplastics as they are transported through the global ocean, and down to its interior (Oberbeckmann et al., 2015). Further microbiological research should be focused on studying plastic degraders in all marine habitats, including those habitats where plastic may accumulate (such as sediments), to exploit the potential of consortia to degrade and mineralize these compounds, and to combine in vitro and field studies with omics technologies to decipher the processes of microbial biodegradation.

\section{ACKNOWLEDGMENTS}

The work was made possible thanks to support granted to GML by the Flagship Programme RITMARE (funded by the Italian Ministry of University and Research), and to GMQ by the SZN and by the research prize "Ricerca il Futuro" funded by Davines (www.ricercailfuturo.it). Metagenomic data were provided by the Ocean Sampling Day project (https://www.microb3.eu/osd.html). GML wish to thank his colleague Giulio Pellini for fruitful and stimulating discussions on this topic.

\section{REFERENCES}

Amaral-Zettler LA, Zettler ER, Slikas B, Boyd GD, Melvin DW, Morrall CE, et al. 2015. The biogeography of the Plastisphere: implications for policy. Front. Ecol. Environ. 13:541-546.

Andrady AL, 2011. Microplastics in the marine environment. Mar. Poll. Bull. 62:1596-1605.

Andrady AL, 2017. The plastic in microplastics: a review. Mar. Poll. Bull. 119:12-22.

Bakir A, Rowland SJ, Thompson RC, 2012. Competitive sorption of persistent organic pollutants onto microplastics in the marine environment. Mar. Poll. Bull. 64:2782-2789. 
Balasubramanian V, Natarajan K, Hemambika B, Ramesh N, Sumathi CS, Kottaimuthu R, Rajesh Kannan V, 2010. Highdensity polyethylene (HDPE)-degrading potential bacteria from marine ecosystem of Gulf of Mannar, India. Lett. Appl. Microbiol. 51:205-211.

Barnes DKA, Galgani F, Thompson RC, Barlaz M, 2009. Accumulation and fragmentation of plastic debris in global environments. Philos. T. R. Soc. Lond. B Biol. 364:1985-1998.

Booth GH, Cooper AW, Robb JA, 1968. Bacterial degradation of plasticized PVC. J. Appl. Microbiol. 31:305-310.

Boucher J, Friot D, 2017. Primary microplastics in the oceans: a global evaluation of sources. IUCN, Gland: 43 pp.

Bryant JA, Clemente TM, Viviani DA, Fong AA, Thomas KA, Kemp P, Karl DM, White AE, DeLong EF, 2016. Diversity and activity of communities inhabiting plastic debris in the North Pacific Gyre. mSystems 1:e00024-16.

Browne MA, Galloway TS, Thompson RC, 2010. Spatial patterns of plastic debris along estuarine shorelines. Environ. Sci. Technol. 44:3404-3409.

Carpenter EJ, Smith KL, 1972. Plastics on the Sargasso Sea surface. Science 175:1240-1241.

Carson HS, Nerheim MS, Carroll KA, Eriksen M, 2013. The plastic-associated microorganisms of the North Pacific Gyre. Mar. Poll. Bull. 75:126-132.

Cau A, Alvito A, Moccia D, Canese S, Pusceddu A, Cannas R, Angiolillo M, Follesa MC, 2017. Submarine canyons along the upper Sardinian slope (Central Western Mediterranean) as repositories for derelict fishing gears. Mar. Poll. Bull. 123:357-364.

Claessens M, De Meester S, Van Landuyt L, De Clerck K, Janssen CR, 2011. Occurrence and distribution of microplastics in marine sediments along the Belgian coast. Mar. Pollut. Bull. 62:2199e2204.

Clark JR, Cole M, Lindeque PK, Fileman E, Blackford J, Lewis C, Lenton TM, Galloway TS, 2016. Marine microplastic debris: a targeted plan for understanding and quantifying interactions with marine life. Front. Ecol. Environ. 14:317-324.

Dang H, Li T, Chen M, Huang G, 2008. Cross-ocean distribution of Rhodobacterales bacteria as primary surface colonizers in temperate coastal marine waters. Appl. Environ. Microbiol. 74:52-60.

Dang HY, Lovell CR, 2000. Bacterial primary colonization and early succession on surfaces in marine waters as determined by amplified rRNA gene restriction analysis and sequence analysis of 16S rRNA genes. Appl. Environ. Microbiol. 66:467-475.

De Tender C, Schlundt C, Devriese LI, Mincer TJ, Zettler ER, Amaral-Zettler LA, 2017. A review of microscopy and comparative molecular-based methods to characterize "Plastisphere" communities. Anal. Methods 9:2132-2143.

De Tender CA, Devriese LI, Haegeman A, Maes S, Ruttink T, Dawyndt P, 2015. Bacterial community profiling of plastic litter in the Belgian part of the North Sea. Environ. Sci. Technol. 49:9629-9638.

Derraik JG. 2002. The pollution of the marine environment by plastic debris: a review. Mar. Pollut. Bull. 44:842-852.

Eriksen M, Lebreton LC. Carson HS, Thiel M, Moore CJ, Borerro JC, Galgani F, Ryan PG, Reisser J, 2014. Plastic pollution in the world's oceans: more than 5 trillion plastic pieces weighing over 250,000 tons afloat at sea. PloS One 9:e111913.
Galgani F, Souplet A, Cadiou Y, 1996. Accumulation of debris on the deep sea floor off the French Mediterranean coast. Mar. Ecol. Progr. Ser. 142:225-234.

Galgani F, Leaute JP, Moguedet P, Souplet A, Verin Y, Carpentier A, et al., 2000. Litter on the sea floor along European coasts. Mar. Poll. Bull. 40:516-527.

GESAMP, 2015. Sources, fate and effects of microplastics in the marine environment: a global assessment. P.J. Kershaw (ed.). IMO/FAO/UNESCO-IOC/UNIDO/WMO/IAEA/ UN/UNEP/UNDP Joint Group of Experts on the Scientific Aspects of Marine Environmental Protection. Rep. Stud. GESAMP No. 90: 96 pp.

Gewert B, Plassmann MM, MacLeod M, 2015. Pathways for degradation of plastic polymers floating in the marine environment. Environ. Sci-Proc. Imp. 17:1513-1521.

Gigault J, Pedrono B, Maxit B, Ter Halle A, 2016. Marine plastic litter: the unanalyzed nano-fraction. Environ. Sci. Nano 3:346-350.

Gregory MR, Ryan PG, 1997. Pelagic plastics and other seaborne persistent synthetic debris: a review of Southern Hemisphere perspectives, p. 49-66. In: J.M. Coe and D.B. Rogers (eds.), Marine Debris. Springer, New York.

Harrison J P, Schratzberger M, Sapp M, Osborn AM, 2014. Rapid bacterial colonization of low-density polyethylene microplastics in coastal sediment microcosms. BMC Microbiol. 14:232.

Harrison JP, Hoellein TJ Sapp M, Tagg AS, Ju-Nam Y, Ojeda JJ, 2018. Microplastic-associated biofilms: a comparison of freshwater and marine environments, p. 181-201. In: M. Wagner, and S. Lambert (eds.), Freshwater microplastics. The Handbook of Environmental Chemistry. Springer, Cham.

Harvey JV, Meloro FA, 1949. Studies of degradation of plastic films by fungi and bacteria. Quartermaster Laboratory Report, Microbiological Series, Washington DC.

Hidalgo-Ruz V, Gutow L, Thompson RC, Thiel M, 2012. Microplastics in the marine environment: a review of the methods used for identification and quantification. Environ. Sci. Technol. 46:3060-3075.

Keswani A, Oliver DM, Gutierrez T, Quilliam RS, 2016. Microbial hitchhikers on marine plastic debris: human exposure risks at bathing waters and beach environments. Mar. Environ. Res. 118:10-19.

Kooi M, Van Nes EH, Scheffer M, Koelmans AA, 2017. Ups and downs in the ocean: effects of biofouling on the vertical transport of microplastics. Environ. Sci. Technol. 51: 963-7971.

Kopf A, Bicak M, Kottmann R, Schnetzer J, Kostadinov I, Lehmann K, et al., 2015. The Ocean Sampling Day consortium. Gigascience 4:1-5.

Krueger MC, Harms H, Schlosser D, 2015. Prospects for microbiological solutions to environmental pollution with plastics. Appl. Microbiol. Biotechnol. 99:8857-8874.

Jambeck JR, Geyer R, Wilcox C, Siegler TR, Perryman M, Andrady A, Narayan R, Law KL. 2015. Plastic waste inputs from land into the ocean. Science 347:768-771.

Law KL, Morét-Ferguson SE, Goodwin DS, Zettler ER, DeForce E, Kukulka T, Proskurowski G. 2014. Distribution of surface plastic debris in the eastern Pacific Ocean from an 11-year data set. Environ. Sci. Technol. 48:4732-4738.

Lee J-W, Nam J-H, Kim Y-H, Lee K-H, Lee D-H, 2008. Bacterial communities in the initial stage of marine biofilm for- 
mation on artificial surfaces. J. Microbiol. 46:174-182.

Lobelle D, Cunliffe M, 2011. Early microbial biofilm formation on marine plastic debris. Mar. Pollut. Bull. 62:197-200.

Mato Y, Isobe T, Takada H, Kanehiro H, Ohtake C, Kaminuma T, 2001. Plastic resin pellets as a transport medium for toxic chemicals in the marine environment. Environ. Sci. Technol. 35:318-324.

Moore CJ, Moore SL, Leecaster MK, Weisberg SB. 2001. A comparison of plastic and plankton in the North Pacific central gyre. Mar. Poll. Bull. 42:1297-1300.

Moore CJ, Moore SL, Weisberg SB, Lattin GL, Zellers AF, 2002. A comparison of neustonic plastic and zooplankton abundance in southern California's coastal waters. Mar. Poll. Bull. 44:1035-1038.

Oberbeckmann S, Loeder MG, Gerdts G, Osborn AM. 2014. Spatial and seasonal variation in diversity and structure of microbial biofilms on marine plastics in northern European waters. FEMS Microbiol. Ecol. 90:478-492.

Oberbeckmann S, Löder MG, Labrenz M, 2015. Marine microplastic-associated biofilms-a review. Environ. Chem. 12:551-562.

Oberbeckmann S, Osborn AM, Duhaime MB, 2016. Microbes on a bottle: substrate, season and geography influence community composition of microbes colonizing marine plastic debris. PLoS One 11:e0159289.

R Core Team, 2017. R: A Language and Environment for Statistical Computing. Available from: https://www.R-project.org/

Reisser J, Shaw J, Hallegraeff G, Proietti M, Barnes DKA, et al., 2014. Millimeter-sized marine plastics: a new pelagic habitat for microorganisms and invertebrates. PLoS One 9:e100289.

Restrepo-Flórez J-M, Bassi A, Thompson MR, 2014. Microbial degradation and deterioration of polyethylene-A review. Intern. Biodeterior. Biodegradation 88:83-90.

Rummel CD, Jahnke A, Gorokhova E, Kühnel D, SchmittJansen M, 2017. The Impacts of biofilm formation on the fate and potential effects of microplastic in the aquatic environment. Environ. Sci. Technol. Lett. 4:258-267.

Singh B, Sharma N, 2008. Mechanistic implications of plastic degradation. Polymer Degrad. Stabil. 93:561-584.

Sivan A, 2011. New perspectives in plastic biodegradation. Curr. Opin. Biotechnol. 22:422-426.

Shah AA, Fariha H, Abdul H, Safia A, 2008. Biological degra- dation of plastics: a comprehensive review. Biotechnol. Adv. 26:2467-2650.

Stefatos A, Charalampakis M, Papatheodorou G, Ferentinos G, 1999. Marine debris on the seafloor of the Mediterranean Sea: examples from two enclosed gulfs in Western Greece. Mar. Poll. Bull. 36:389-393.

Sundt P, Schulze P-E, Syversen F, 2014. Sources of microplastics-pollution to the marine environment. Norvegian Environ. Agency, Mepex 1032: pp. 86.

Syranidou E, Karkanorachaki K, Amorotti F, Repouskou E, Kroll K, Kolvenbach B, et al., 2017. Development of tailored indigenous marine consortia for the degradation of naturally weathered polyethylene films. PLoS One 12 e0183984.

Taylor ML, Gwinnett C, Robinson LF, Woodall LC, 2016. Plastic microfibre ingestion by deep-sea organisms. Sci. Rep. 6: 33997.

Ter Halle A, Jeanneau L, Martignac M, Jardé E, Pedrono B, Brach L, Gigault J, 2017. Nanoplastic in the North Atlantic Subtropical Gyre. Environ. Sci. Technol. 51:13689-13697.

Van Cauwenberghe L, Devriese L, Galgani F, Robbens J, Janssen CR, 2015. Microplastics in sediments: a review of techniques, occurrence and effects. Mar. Environ. Res. 111:5-17.

van der Hal N, Ariel A, Angela DL, 2017. Exceptionally high abundances of microplastics in the oligotrophic Israeli Mediterranean coastal waters. Mar. Pollut. Bull. 116:151-155.

Willis K, Hardesty BD, Kriwoken L, Wilcox C, 2017. Differentiating littering, urban runoff and marine transport as sources of marine debris in coastal and estuarine environments. Sci. Rep. 7:44479.

Worm B, Lotze HK, Jubinville I, Wilcox C, Jambeck J, 2017. Plastic as a persistent marine pollutant. Ann. Rev. Environ. Resour. 42:1-26.

Woodall LC, Sanchez-Vidal A, Canals M, Paterson GL, Coppock R, Sleight V, et al., 2014. The deep sea is a major sink for microplastic debris. Royal Soc. Open Sci. 1:140317.

Yoshida S, Hiraga K, Takehana T, Taniguchi I, Yamaji H, Maeda Y. Toyohara K, Miyamoto K, Kimura Y, Oda K, 2016. A bacterium that degrades and assimilates poly (ethylene terephthalate). Science 351:1196-1199.

Zettler ER, Mincer TJ, Amaral-Zettler LA, 2013. Life in the "Plastisphere": microbial communities on plastic marine debris. Environ. Sci. Technol. 47:7137-7146. 